\title{
Electronic Structure with Rovibrational and Dipole Moment Study of the NiO Molecule
}

\author{
Khalil Badreddine $^{1}$, Nayla El-Kork ${ }^{2}$, Mahmoud Korek ${ }^{1^{*}}$ \\ ${ }^{1}$ Faculty of Science, Beirut Arab University, Riad El Solh, Beirut, Lebanon \\ ${ }^{2}$ Khalifa University, Sharjah, UAE \\ Email: "fkorek@yahoo.com
}

Received June 10, 2012; revised July 9, 2012; accepted July 31, 2012

\begin{abstract}
The potential energy curves have been investigated for the 40 lowest electronic states in the ${ }^{2 s+1} \Lambda^{( \pm)}$representation below $25,000 \mathrm{~cm}^{-1}$ of the molecule $\mathrm{NiO}$ via CASSCF, MRCI (single and double excitation with Davidson correction) and CASPT2 methods. The harmonic frequency $\omega_{e}$, the internuclear distance $r_{e}$, the rotational constant $B_{e}$, the electronic energy with respect to the ground state $T_{e}$, and the permanent dipole moment $\mu$ have been calculated. By using the canonical functions approach, the eigenvalues $E_{v}$, the rotational constant $B_{v}$ and the abscissas of the turning points $r_{\min }$ and $r_{\max }$ have been calculated for the considered electronic states up to the vibration level $v=12$. Eleven electronic states have been studied theoretically here for the first time. The comparison of these values to the theoretical and experimental results available in literature shows a very good agreement.
\end{abstract}

Keywords: Ab Initio Calculation; NiO Molecule; Potential Energy Curves; Spectroscopic Constants; Dipole Moment; Rovibrational Calculation

\section{Introduction}

The metal oxide $\mathrm{NiO}$ shows complicated electronic spectra because of the presence of large number of electronic states derived from several low-lying configurations but it gives a systematic example of chemical bonding, which depends on the relative energy between the $3 d$ orbital of the metal and the $2 p$ orbital of oxygen $[1,2]$. The transition metal oxides have interesting applications in many fields such as materials application and the oxidation of metal surfaces. Among these compounds the NiO molecule which is considered as a prototype of ionic crystals, it is classified as a Mott-Hubbard insulator of very low conductivity. The conductivity of nanostructred $\mathrm{NiO}$ was found to be enhanced by six to eight orders of magnitude over those of $\mathrm{NiO}$ single crystals [3-10]. The magnetic properties of different sizes of $\mathrm{NiO}$ nanoparticles reveal the presence of superparamagnetism as evidenced by the increasing magnetization with decreasing size as well as the magnetic hysteresis at low temperatures. Nanomagnetism promises have applications in magnetic storage with nanomagnetic particles, improved battery lifetimes and also quantum computing [11-14]. The nanoarticles formed by the $\mathrm{NiO}$ molecule have many applications in electronics, optical, electro-optical devices and photo-

${ }^{*}$ Corresponding author. catalytic reaction. Despite this importance of the nickel oxide $\mathrm{NiO}$, this molecule has been studied experimenttally and theoretically [15-35] where a limited number of electronic states have been obtained with the corresponding molecular constants. The theoretical calculation of the $\mathrm{NiO}$ molecule is an extreme computational challenge because of the degeneracy of several energetically low-lying excited states and the open $d, p$, and $s$ shells. The presence of the $d$ shell implies large multiplicities which are split by spin-orbit interaction. The components of the spin and the many states perturb each other. The prediction and assignment of the electronic configuration in the ground and excited states and the description of the bonding may often be difficult.

Based on our previous theoretical calculation [36-45], the important connection between energy relations of solids and molecules [46], and stimulated by the lack of theoretical calculation of excited electronic states with the existence of preliminary experimental and theoretical data, we performed an $a b$ initio study of the low-lying electronic states of the molecule $\mathrm{NiO}$ below $25,000 \mathrm{~cm}^{-1}$. In this work, we investigate the potential energy curves (PECs), the electric dipole moment and spectroscopic constants for the $40{ }^{2 s+1} \Lambda^{( \pm)}$low-lying electronic states of this molecule obtained by MRCI and RSPT2 calculations. Taking advantage of the electronic structure of the inves- 
tigated electronic states of the $\mathrm{NiO}$ molecule and by using the canonical functions approach [47], the eigenvalues $E_{v}$, the rotational constant $B_{v}$ and the abscissas of the turning points $r_{\min }$ and $r_{\max }$ have been calculated for several vibrational levels of the considered electronic states.

\section{Computational Approach}

\subsection{Ab Initio Calculation}

The PECs of the lowest-lying electronic states of the $\mathrm{NiO}$ molecule have been investigated via CASSCF and CASPT2 methods. The MRCI calculations (single and double excitations with Davidson corrections) were performed. The Nickel atom is treated as a system with 10 inner electrons taken into account using the basis LANL2DZECP [48] for $s, p$ and $d$ functions. The 8 electrons of the oxygen atom are considered using the DGauss- $\mathrm{a}_{2}-\mathrm{Xfit}$ [49] basis set including s, p and d functions. Among the 26 electrons explicitly considered for the $\mathrm{NiO}$ molecule (18 electrons for $\mathrm{Ni}$ and 8 for $\mathrm{O}$ ), 14 inner electrons were frozen in subsequent calculations so that 12 valence electrons were explicitly treated. This calculation has been performed via the computational chemistry program MOLPRO [50] taking advantage of the graphical user interface GABEDIT [51].

In the representation ${ }^{2 s^{+1}} \Lambda^{( \pm)}, 40$ electronic states have been investigated for 46 internuclear distances in the range $1.331 \AA \leq r \leq 2.681 \AA$ by using the MRCI and RSPT2 calculations. The potential energy curves for the singlet and triplet states, obtained by MRCI calculation, are given in Figures 1-4.

The spectroscopic constants such as the vibration harmonic constant $\omega_{e}$, the internuclear distance at equilibrium $r_{e}$, the rotational constant $B_{e}$ and the electronic transition energy with respect to the ground state $T_{e}$ have been calculated by fitting the energy values around the equilibrium position to a polynomial in terms of the internuclear distance. These values are given in Table 1 together with the available data in the literature either theoretical or experimental.

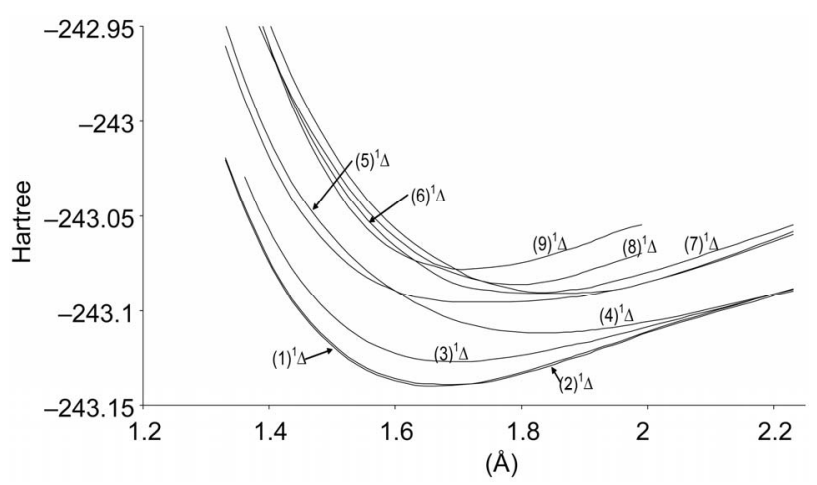

Figure 1. Potential energy curves of the lowest singlet ${ }^{1} \Delta$ and ${ }^{1} \Sigma$ states of the molecule $\mathrm{NiO}$.

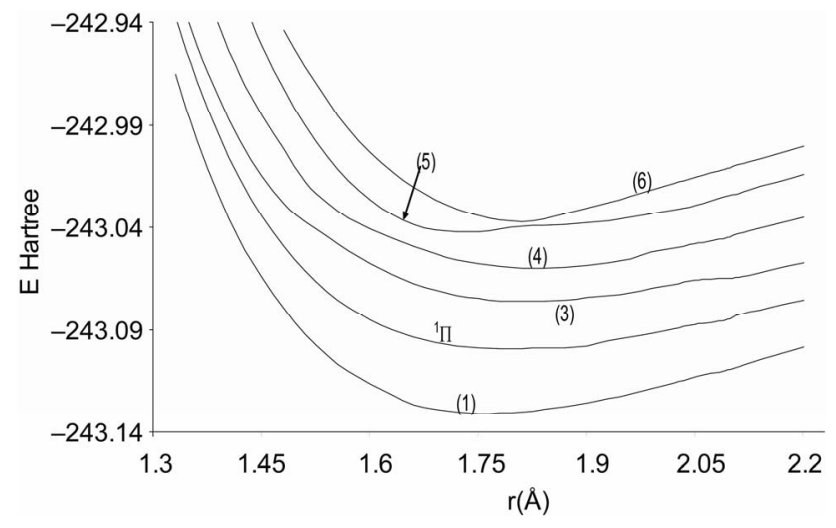

Figure 2. Potential energy curves of the lowest singlet ${ }^{1} \Pi$ states of the molecule NiO.

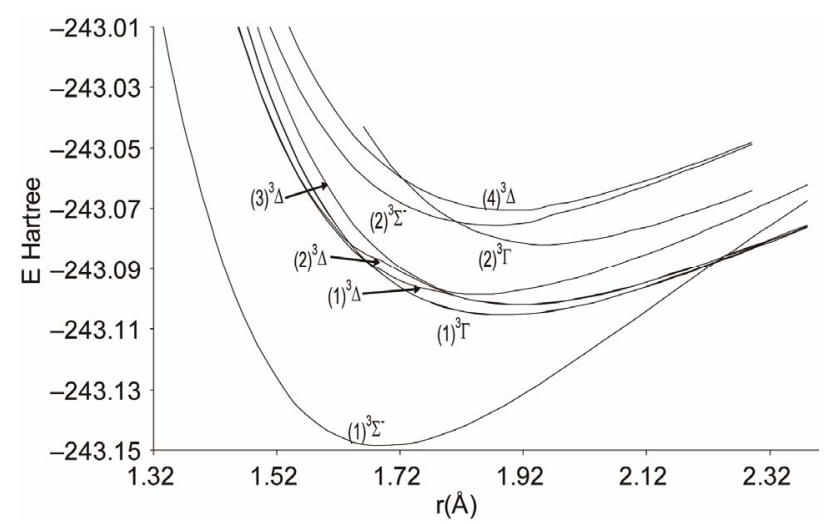

Figure 3. Potential energy curves of the lowest triplet ${ }^{3} \Sigma^{-},{ }^{3} \Delta$ and ${ }^{3} \Gamma$ states the molecule NiO.

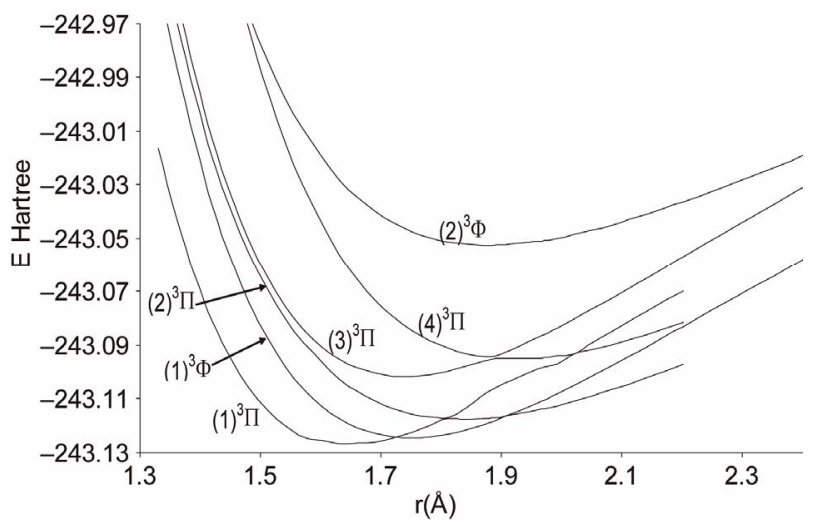

Figure 4. Potential energy curves of the lowest triplet ${ }^{3} \Pi$ and ${ }^{3} \Phi$ states of the molecule NiO.

An overlap between the $3 d$ and $4 s$ orbitals of the $\mathrm{Ni}$ atom and the $2 p$ orbitals of the oxygen atom lead to the formation of the molecular orbitals of the molecule $\mathrm{NiO}$. The ground state of this molecule is confirmed theoreticcally and experimentally to be $a^{3} \Sigma^{-}[1,16-23,34-35$, 52-58], its electronic configuration can approximately described as $8 \sigma^{2} 3 \pi^{4} 1 \delta^{4} 9 \sigma^{2} 4 \pi^{2}$. The $9 \sigma$ and $4 \pi$ orbitals are antibonding, the $1 \delta$ orbital is nonbonding, and the 
Table 1. Spectroscopic constants for the electronic states of the molecule NiO.

\begin{tabular}{|c|c|c|c|c|}
\hline States & $T_{e}\left(\mathrm{~cm}^{-1}\right)$ & $r_{e}(\AA)$ & $\omega_{e}\left(\mathrm{~cm}^{-1}\right)$ & $B_{e}\left(\mathrm{~cm}^{-1}\right)$ \\
\hline \multirow[t]{24}{*}{$\mathrm{X}^{3} \Sigma^{-}$} & $0.0^{\mathrm{a} 1}$ & $1.690^{\mathrm{a} 1}$ & $768.0^{\mathrm{a} 1}$ & $0.469^{\mathrm{a} 1}$ \\
\hline & $0.0^{\mathrm{a} 2}$ & $1.774^{\mathrm{a} 2}$ & $634.6^{\mathrm{a} 2}$ & $0.426^{\mathrm{a} 2}$ \\
\hline & $0.0^{\mathrm{b} 1}$ & $1.627^{\mathrm{b} 1}$ & & \\
\hline & $0.0^{\mathrm{b} 2}$ & $1.626^{\mathrm{b} 2}$ & $840^{\mathrm{b} 2}$ & \\
\hline & $0.0^{\mathrm{b3}}$ & & $800(50)^{\mathrm{b} 3}$ & \\
\hline & $0.0^{\mathrm{b} 4}$ & $1.640^{\mathrm{b} 4}$ & & \\
\hline & $0.0^{\mathrm{b} 5}$ & $1.627^{\mathrm{b5}}$ & $839.1^{\mathrm{b} 5}$ & $0.58^{\mathrm{b} 5}$ \\
\hline & $0.0^{\mathrm{c}}$ & & $841^{\mathrm{c}}$ & \\
\hline & $0.0^{\mathrm{d}}$ & $1.626^{\mathrm{d}}$ & $850^{\mathrm{d}}$ & \\
\hline & $0.0^{\mathrm{e}}$ & $1.589^{\mathrm{e}}$ & $1068^{\mathrm{e}}$ & \\
\hline & $0.0^{\mathrm{g}}$ & $1.631^{\mathrm{g}}$ & $838^{\mathrm{g}}$ & \\
\hline & $0.0^{\mathrm{h}}$ & $1.627^{\mathrm{h}}$ & & \\
\hline & $0.0^{\mathrm{i}}$ & & $839.69^{\mathrm{i}}$ & \\
\hline & $0.0^{\mathrm{j} 1}$ & $1.61^{\mathrm{j} 1}$ & $876^{\mathrm{j}^{1}}$ & \\
\hline & $0.0^{\mathrm{j} 2}$ & $1.60^{\mathrm{j} 2}$ & $907^{\mathrm{j}^{2}}$ & $0.5800(3)^{\mathrm{i}}$ \\
\hline & $0.0^{\mathrm{j} 3}$ & $1.60^{\mathrm{j} 3}$ & $903^{\mathrm{j} 3}$ & \\
\hline & $0.0^{\mathrm{j} 4}$ & $1.64^{j 4}$ & $829^{j^{4}}$ & \\
\hline & $0.0 \mathrm{k}$ & $1.644^{\mathrm{k}}$ & $823^{\mathrm{k}}$ & \\
\hline & $0.0^{\mathrm{L} 1}$ & $1.682^{\mathrm{L} 1}$ & $748^{\mathrm{L} 1}$ & \\
\hline & $0.0^{\mathrm{L} 2}$ & $1.608^{\mathrm{L} 2}$ & $906^{\mathrm{L} 2}$ & \\
\hline & $0.0^{\mathrm{L} 3}$ & $1.784^{\mathrm{L} 3}$ & $848^{\mathrm{L} 3}$ & \\
\hline & $0.0^{\mathrm{m}}$ & & $615^{\mathrm{m}}$ & \\
\hline & $0.0^{\mathrm{P}}$ & & $837.61^{\mathrm{p}}$ & \\
\hline & & & $839.69^{\mathrm{s}}$ & \\
\hline$(1)^{1} \Delta$ & $1956.3^{\mathrm{a} 1}$ & $1.666^{\mathrm{a} 1}$ & $802.4^{\mathrm{a} 1}$ & $0.483^{\mathrm{a} 1}$ \\
\hline$(1)^{3} \Gamma$ & $2036.8^{\mathrm{a} 2}$ & $1.921^{\mathrm{a} 2}$ & $492.6^{\mathrm{a} 2}$ & $0.363^{\mathrm{a} 2}$ \\
\hline \multirow[t]{2}{*}{$(2)^{1} \Delta$} & $2134.5^{\mathrm{a} 1}$ & $1.681^{\mathrm{a} 1}$ & $706.7^{7^{1}}$ & $0.475^{\mathrm{a} 1}$ \\
\hline & $2524.3^{\mathrm{b} 1}$ & $1.66(1)^{\mathrm{b} 1}$ & & \\
\hline$(1)^{3} \Phi$ & $2305.8^{\mathrm{a} 2}$ & $1.814^{\mathrm{a} 2}$ & $624.2^{\mathrm{a} 2}$ & $0.408^{\mathrm{a} 2}$ \\
\hline${ }^{1} \Pi$ & $2708.0^{\mathrm{a} 2}$ & $1.890^{\mathrm{a} 2}$ & $550.3^{\mathrm{a} 2}$ & $0.375^{\mathrm{a} 2}$ \\
\hline${ }^{1} \Phi$ or ${ }^{1} \Pi$ & $3837.4^{\mathrm{a} 1}$ & $1.752^{\mathrm{a} 1}$ & $668.2^{\mathrm{a} 1}$ & $0.437^{\mathrm{a} 1}$ \\
\hline (1) ${ }^{1} \Gamma$ & $4243.7^{\mathrm{a} 2}$ & $1.914^{\mathrm{a} 2}$ & $529.7^{\mathrm{a} 2}$ & $0.366^{\mathrm{a} 2}$ \\
\hline (3) ${ }^{1} \Delta$ & $4779.3^{\mathrm{a} 1}$ & $1.693^{\mathrm{a} 1}$ & $685.8^{\mathrm{a} 1}$ & $0.468^{\mathrm{a} 1}$ \\
\hline${ }^{1} \Delta$ & $4970.3^{\mathrm{a} 2}$ & & $485.3^{\mathrm{a} 2}$ & $0.359^{\mathrm{a} 2}$ \\
\hline$(1)^{3} \Pi$ & $5068.6^{\mathrm{a} 2}$ & $1.958^{\mathrm{a} 2}$ & $435.8^{\mathrm{a} 2}$ & $0.349^{\mathrm{a} 2}$ \\
\hline${ }^{3} \Pi_{2}$ & $3915.9^{\mathrm{bl}}$ & $1.645^{\mathrm{b} 1}$ & & \\
\hline${ }^{3} \Pi_{1}$ & $4327.3^{\mathrm{b} 1}$ & $1.645^{\mathrm{b} 1}$ & & \\
\hline${ }^{3} \Pi(\Omega=1)$ & $4293.8^{\mathrm{b} 2}$ & $1.644^{\mathrm{b} 2}$ & $777^{\mathrm{b} 2}$ & \\
\hline$(1)^{3} \Pi_{2}$ & $3500.5^{\mathrm{b} 3}$ & & & \\
\hline$(1)^{3} \Pi_{1}$ & $3992.5^{\mathrm{b} 3}$ & & & \\
\hline$(1)^{3} \Pi_{0}$ & $4484.5^{\mathrm{b} 3}$ & & & \\
\hline $\mathrm{A}^{3} \Pi_{\mathrm{i}}$ & $4337.55546^{\mathrm{h}}$ & $1.6449^{\mathrm{h}}$ & $780.8^{\mathrm{h}}$ & $0.4970^{\mathrm{h}}$ \\
\hline${ }^{3} \Pi$ & $4293.78(5)^{\mathrm{i}}$ & & $777.10(5)^{\mathrm{i}}$ & $0.49701(2)^{\mathrm{i}}$ \\
\hline${ }^{3} \Pi$ & & $1.633^{\mathrm{e}}$ & $947^{\mathrm{e}}$ & \\
\hline${ }^{3} \Pi$ & & & $540^{\mathrm{q}}$ & \\
\hline${ }^{3} \Pi$ & $3260^{\mathrm{n}}$ & & & \\
\hline
\end{tabular}


Continued

\begin{tabular}{|c|c|c|c|c|}
\hline${ }^{3} \Pi$ & & $1.64^{\mathrm{j}}$ & $787^{\mathrm{j}}$ & \\
\hline \multirow[t]{2}{*}{$(2)^{3} \Phi$} & $5271.9^{\mathrm{a} 1}$ & $1.749^{\mathrm{a} 1}$ & $692.6^{\mathrm{a} 1}$ & $0.4382^{\mathrm{al}}$ \\
\hline & $5230.6^{\mathrm{b} 1}$ & $1.66(2)^{\mathrm{b} 1}$ & & \\
\hline${ }^{3} \Phi(\Omega=4)$ & $3468.3<\mathrm{Te}<4274.8^{\mathrm{b} 2}$ & & & \\
\hline${ }^{3} \Phi(\Omega=3)$ & $5250.8^{\mathrm{b} 2}$ & & & \\
\hline${ }^{3} \Phi(\Omega=2)$ & $6218.7^{\mathrm{b} 2}$ & & & \\
\hline$(1)^{1} \Pi$ & $5664.91^{\mathrm{a} 1}$ & $1.642^{\mathrm{a} 1}$ & $727.6^{\mathrm{a} 1}$ & $0.4982^{\mathrm{al}}$ \\
\hline$(2)^{3} \Pi$ & $6790.9^{\mathrm{a} 1}$ & $1.835^{\mathrm{a} 1}$ & $544.4^{\mathrm{a} 1}$ & $0.3981^{\mathrm{al}}$ \\
\hline$\left({ }^{3} \Phi_{4},{ }^{3} \Delta_{3},{ }^{3} \Pi_{2}\right)$ & $7659.2^{\mathrm{b} 1}$ & $1.66(2)^{\mathrm{b} 1}$ & & \\
\hline$\left({ }^{3} \Phi_{3},{ }^{3} \Delta_{2},{ }^{3} \Pi_{1}\right)$ & $8232.7^{\mathrm{b} 1}$ & $1.66(2)^{\mathrm{b} 1}$ & & \\
\hline$\left({ }^{3} \Phi_{2},{ }^{3} \Delta_{1},{ }^{3} \Pi_{0}\right)$ & $8788.4^{\mathrm{b} 1}$ & $1.66(2)^{\mathrm{b} 1}$ & & \\
\hline${ }^{3} \Pi$ & $\approx 6000^{\mathrm{c}}$ & & & \\
\hline (4) $)^{1}$ & $8091.0^{\mathrm{a} 1}$ & $1.829^{\mathrm{a} 1}$ & $581.6^{\mathrm{a} 1}$ & $0.4008^{\mathrm{al}}$ \\
\hline${ }^{1} \Delta$ & $7581.2^{\mathrm{b} 2}$ & $1.600(6)^{\mathrm{b} 2}$ & $615(15)^{\mathrm{b} 2}$ & \\
\hline $\mathrm{a}\left({ }^{1} \Delta\right)$ & $7614.1^{\mathrm{b3}}$ & & $680(60)^{\mathrm{b3}}$ & \\
\hline$(1)^{3} \Gamma$ & $9454.1^{\mathrm{a} 1}$ & $1.887^{\mathrm{a} 1}$ & $539.7^{\mathrm{a} 1}$ & $0.3764^{\mathrm{al}}$ \\
\hline$(2)^{3} \Gamma$ & $9471.6^{\mathrm{a} 1}$ & $1.887^{\mathrm{a} 1}$ & $540.7^{\mathrm{a} 1}$ & $0.3765^{\mathrm{al}}$ \\
\hline$(3)^{3} \Pi$ & $10276.4^{\mathrm{al}}$ & $1.740^{\mathrm{a} 1}$ & $714.4^{\mathrm{a} 1}$ & $0.4425^{\mathrm{al}}$ \\
\hline$(3)^{3} \Pi$ & $9552.7^{\mathrm{a} 2}$ & $1.795^{\mathrm{a} 2}$ & $804.8^{\mathrm{a}^{2}}$ & $0.4163^{\mathrm{a} 2}$ \\
\hline${ }^{3} \Pi(\Omega=0)$ & $9449.1^{\mathrm{b} 2}$ & & & \\
\hline${ }^{3} \Pi(\Omega=1)$ & $9848.5^{\mathrm{b} 2}$ & $1.66(2)^{\mathrm{b} 1}$ & & \\
\hline${ }^{3} \Pi(\Omega=2)$ & $10090.2^{\mathrm{b} 2}$ & & & \\
\hline$(1)^{3} \Delta$ & $10185.1^{\mathrm{a} 1}$ & $1.917^{\mathrm{a} 1}$ & $598.1^{\mathrm{a} 1}$ & $0.3648^{\mathrm{al}}$ \\
\hline${ }^{3} \Delta$ & & $1.616^{\mathrm{e}}$ & $991^{\mathrm{e}}$ & \\
\hline${ }^{3} \Delta$ & & & $580^{\mathrm{d}}$ & \\
\hline$(2)^{3} \Delta$ & $10243.65^{\mathrm{a} 1}$ & $1.918^{\mathrm{al}}$ & $504.7^{\mathrm{a} 1}$ & $0.3642^{\mathrm{a} 1}$ \\
\hline$(2)^{1} \Pi$ & $10823.3^{\mathrm{a} 1}$ & $1.807^{\mathrm{a} 1}$ & $448.7^{\mathrm{a} 1}$ & $0.4101^{\mathrm{al}}$ \\
\hline${ }^{1} \Pi_{1}$ & $10095.1^{\mathrm{b} 1}$ & $1.66(2)^{\mathrm{b} 1}$ & & \\
\hline$(3)^{3} \Delta$ & $10945.1^{\mathrm{al}}$ & $1.850^{\mathrm{a} 1}$ & $683.5^{\mathrm{a} 1}$ & $0.3918^{\mathrm{a} 1}$ \\
\hline$(5)^{1} \Delta$ & $11690.0^{\mathrm{a} 1}$ & $1.737^{\mathrm{a} 1}$ & $419.8^{\mathrm{a} 1}$ & $0.4459^{\mathrm{a} 1}$ \\
\hline$(4)^{3} \Pi$ & $11723.3^{\mathrm{a} 1}$ & $1.922^{\mathrm{a} 1}$ & $556.7^{\mathrm{a} 1}$ & $0.3630^{\mathrm{a} 1}$ \\
\hline${ }^{1} \Sigma^{+}$ & $11803.4^{\mathrm{a} 2}$ & $1.902^{\mathrm{a} 2}$ & $528.5^{\mathrm{a} 2}$ & $0.371^{\mathrm{a} 2}$ \\
\hline$(6)^{1} \Delta$ & $12686.6^{\mathrm{a} 1}$ & $1.840^{\mathrm{a} 1}$ & $382.9^{\mathrm{a} 1}$ & $0.3940^{\mathrm{a} 1}$ \\
\hline$(6)^{1} \Delta$ & $12687.6^{\mathrm{a} 2}$ & $1.939^{\mathrm{a}^{2}}$ & $569.8^{\mathrm{a} 2}$ & $0.3560^{\mathrm{a} 2}$ \\
\hline$(7)^{1} \Delta$ & $12852.8^{\mathrm{a} 1}$ & $1.835^{\mathrm{a}}$ & $813.9^{a 1}$ & $0.3982^{\mathrm{a} 1}$ \\
\hline$(8)^{1} \Delta$ & $13715.2^{\mathrm{a} 1}$ & $1.798^{\mathrm{al}}$ & $904.78^{\mathrm{a} 1}$ & $0.4146^{\mathrm{a} 1}$ \\
\hline$(3)^{3} \Phi$ & $13911.9^{\mathrm{a} 2}$ & $1.901^{\mathrm{a} 2}$ & $541.15^{\mathrm{a} 2}$ & $0.3707^{\mathrm{a} 2}$ \\
\hline $\mathrm{B}\left({ }^{3} \Phi\right)$ & $10025.7^{\mathrm{b} 3}$ & & & \\
\hline${ }^{1} \Sigma^{+}$ & $14595.5^{\mathrm{a} 1}$ & $1.967^{\mathrm{a} 1}$ & $533.1^{\mathrm{a} 1}$ & $0.3462^{\mathrm{al}}$ \\
\hline $\mathrm{b} 1\left({ }^{1} \Sigma^{+}\right)$ & $14526.4^{\mathrm{b} 3}$ & & & \\
\hline${ }^{1} \Sigma^{+}$ & & $1.669^{\mathrm{e}}$ & $864^{\mathrm{e}}$ & \\
\hline${ }^{1} \Sigma^{+}$ & & & $560^{q}$ & \\
\hline${ }^{1} \Phi$ & $15460.2^{\mathrm{a} 2}$ & $1.901^{\mathrm{a} 2}$ & $536.53^{\mathrm{a} 2}$ & $0.371^{\mathrm{a} 2}$ \\
\hline${ }^{1} \Pi$ & $15923.6^{\mathrm{a} 1}$ & $1.815^{\mathrm{a} 1}$ & $594.2^{\mathrm{a} 1}$ & $0.4066^{\mathrm{al}}$ \\
\hline$(2)^{3} \Sigma^{-}$ & $16053.6^{\mathrm{a} 1}$ & $1.870^{\mathrm{a} 1}$ & & \\
\hline${ }^{3} \Sigma^{-}$ & $16000.0^{\mathrm{i}}$ & & & \\
\hline $\mathrm{A}^{3} \Sigma^{-}$ & $16075.0^{\mathrm{S}}$ & & $617.0^{\mathrm{s}}$ & \\
\hline
\end{tabular}


Continued

\begin{tabular}{|c|c|c|c|c|}
\hline$(4)^{3} \Delta$ & $17094.3^{\mathrm{a} 1}$ & $1.904^{\mathrm{a} 1}$ & $528.9^{\mathrm{a} 1}$ & $0.3695^{\mathrm{al}}$ \\
\hline${ }^{3} \Delta$ & & $1.616^{\mathrm{e}}$ & $991^{\mathrm{e}}$ & \\
\hline${ }^{3} \Delta$ & & & $580^{9}$ & \\
\hline$(3)^{1} \Pi$ & $19452.6^{\mathrm{a} 1}$ & $1.830^{\mathrm{a} 1}$ & $639.8^{\mathrm{a} 1}$ & $0.4001^{\mathrm{al}}$ \\
\hline${ }^{1} \Pi$ & $19447.3^{\mathrm{a} 2}$ & $1.775^{\mathrm{a} 2}$ & $641.1^{\mathrm{a} 2}$ & $0.4256^{\mathrm{a} 2}$ \\
\hline$\left({ }^{1} \Pi\right)$ & $19204.5^{\mathrm{b} 3}$ & & & \\
\hline${ }^{1} \Pi$ & $20828.2^{\mathrm{a} 2}$ & $1.867^{\mathrm{a} 2}$ & $617.6^{\mathrm{a} 2}$ & $0.3848^{\mathrm{a} 2}$ \\
\hline$(4)^{3} \Phi$ & $21073.1^{\mathrm{a} 1}$ & $1.879^{\mathrm{a} 1}$ & $541.3^{\mathrm{a} 1}$ & \\
\hline${ }^{1} \Pi$ & $23088.9^{\mathrm{a} 2}$ & $1.897^{\mathrm{a} 2}$ & $537.2^{\mathrm{a} 2}$ & $0.3725^{\mathrm{a} 2}$ \\
\hline${ }^{1} \Phi$ & $24177.4^{\mathrm{a} 2}$ & $1.909^{\mathrm{a} 2}$ & $618.0^{\mathrm{a} 2}$ & $0.3671^{\mathrm{a} 2}$ \\
\hline${ }^{1} \Pi$ & $24600.9^{\mathrm{a} 2}$ & $1.951^{\mathrm{a} 2}$ & $544.0^{\mathrm{a} 2}$ & $0.3525^{\mathrm{a} 2}$ \\
\hline
\end{tabular}

${ }^{\mathrm{a} 1}$ For the present work with MRCI calculation; ${ }^{\mathrm{A} 2}$ For the present work with CASPT2 calculation; ${ }^{\mathrm{b} 1}$ Ref. $52 ;{ }^{\mathrm{b} 2}$ Ref. $53 ;{ }^{\mathrm{b} 3}$ Ref.

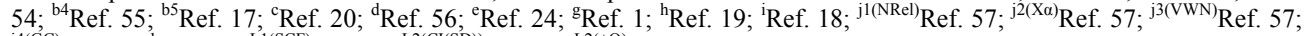
${ }_{\mathrm{j} 4(\mathrm{GC})}$ Ref. 57; ${ }^{\circ}$ Ref. 34; ${ }^{\mathrm{L} 1(\mathrm{SCF})}$ Ref. 23; ${ }^{\mathrm{L}(\mathrm{CI}(\mathrm{SD}))}$ Ref. 23; ${ }^{\mathrm{L}(+\mathrm{Q})}$ Ref. 23; ${ }^{\mathrm{m}}$ Ref. 35; ${ }^{\mathrm{n}}$ Ref. 21; ${ }^{\mathrm{p}}$ Ref. 16; ${ }^{\mathrm{q}}$ Ref. 22; ${ }^{\mathrm{s}}$ Ref. 58.

remaining orbitals are bonding [53]. The electronic structure of all the open shell $3 d$ oxide are dominated by $\mathrm{M}^{2+} \mathrm{O}^{2-}$ zero-order character at low energy, while the $\mathrm{NiO}$ molecule has the chance to be represented by $\mathrm{Ni}^{+} \mathrm{O}^{-}$ atomic-ion-in-molecule model [18]. Our calculated values of the internuclear distance $r_{e}$ and the vibrational harmonic constant $\omega_{e}$, for the ground state, by using the MRCI calculation, are in very good agreement with the experimental values in literature with the relative differences $2.7 \%$ (Ref. [34]) $<\Delta r_{e} / r_{e}<3.8 \%$ (Ref. [53]) and $4 \%$ (Ref. [53]) $<\Delta \omega_{e} / \omega_{e}<8.5 \%$ (Ref. [18]) respectively. These relative differences become larger by using the CASPT2 method where $7.3 \%$ (Ref. [34]) $<\Delta r_{e} / r_{e}<$ $8.3 \%$ (Ref. [53]) and 20.6\% (Ref. [54]) $<\Delta \omega_{e} / \omega_{e}<$ $24.4 \%$ (Ref. [18]), but the value of $\omega_{e}$ given by Huber and Herzberg [35] is in very good agreement with our value calculated by CASPT2 method where $\Delta \omega_{e} / \omega_{e}=$ $3 \%$ and bad agreement with the value calculated by the MRCI method with $\Delta \omega_{e} / \omega_{e}=20 \%$. By comparing our calculated values of $r_{e}$ with those calculated theoretically in literature we obtained a very good agreement with relative differences 3.8\% (Ref. [56]) $<\Delta r_{e} / r_{e}<5.6 \%$ (Ref. [23]) and $0.5 \%$ (Ref. [23]) $<\Delta r_{e} / r_{e}<8.3 \%$ (Ref. [56]) calculated by MRCI and CASPT2 respectively, while the theoretical values of $\omega_{e}$ calculated in literature varies between 748 and $1068 \mathrm{~cm}^{-1}$ and our values are in agreement with the lower value.

A large number of low-lying electronic states, many with very high spin multiplicity, of $3 d$ metal oxides are produced by the unpaired electrons, therefore strong state mixing results in spectroscopy which implies difficult theoretical calculation. Another dimension of complexity can be added originating for the large nuclear spin and magnetic moment of the nuclei with odd atomic number. The first excited state of the $\mathrm{NiO}$ molecules has long been a matter of controversy. The theoretical calculation of Bauschlicher Jr. and collaborators $[21,22,56]$ and that of Bakalbassis et al. [24] found that the first excited state of this molecule is ${ }^{3} \Pi$. Moravec and Jarrold [53] and $\mathrm{Wu}$ and Wang [54] confirmed experimentally that ${ }^{3} \Pi$ is the first excited state. For Ram and Bernath [19] and Freidman-Hill and Field [18] this ${ }^{3} \Pi$ state is located experimentally above the ground state $\mathrm{X}^{3} \Sigma^{-}$at 4330 and 4293 $\mathrm{cm}^{-1}$ respectively. From the photoelectron spectroscopy technique, Ramond et al. located the ${ }^{3} \Pi_{2}$ and ${ }^{3} \Pi_{1}$ at 3916 and $4327 \mathrm{~cm}^{-1}$ respectively [52]. By a theoretical calculation, Walch and Goddard [20] predicted that the first excited state is ${ }^{1} \Pi$ rather than ${ }^{3} \Pi$ and located this state at $6000 \mathrm{~cm}^{-1}$ above the ground state $\mathrm{X}^{3} \Sigma^{-}$. This prediction of Walch and Goddard [20] for the first excited state ${ }^{1} \Delta$ is in agreement with the present work but our ${ }^{3} \Pi$ state is located at $5068.6 \mathrm{~cm}^{-1}$ above the ground state. Moreover between the first excited state (1) $)^{1} \Delta$ and the $(1)^{3} \Pi$ we found the 4 new singlet electronic states (1) ${ }^{1} \Delta,(2)^{1} \Delta$, ${ }^{1} \Phi$ or ${ }^{1} \Pi$ and $(3)^{1} \Delta$ by using MRCI calculation and the 2 new triplet electronic states $(1)^{3} \Gamma,(1)^{3} \Phi$, and the 3 new singlet electronic states ${ }^{1} \Pi(1)^{1} \Gamma$ and ${ }^{1} \Delta$ by using RSPT2 calculation. The agreement between the 2 ways of calculation is only for the last state ${ }^{1} \Delta$. Ramond et al. [52] investigated an electronic state at $2525 \mathrm{~cm}^{-1}$ between $\mathrm{X}^{3} \Sigma^{-}$and ${ }^{3} \Pi_{2}$ states without assigning the nature of this state. By comparing the data of this state with our calculated values, one can find that, it is either $(2)^{1} \Delta$ or $(1)^{3} \Phi$.

Also without assigning the name of the state, Ramond et al. [52] detected the energy $5230.6 \mathrm{~cm}^{-1}$ above the ${ }^{3} \Pi_{1}$, this energy is in very good agreement with the energy of our calculated $(2)^{3} \Phi$ state with the relative differences $\Delta T_{e} / T_{e}=0.8 \%$ and $\Delta r_{e} / r_{e}=5 \%$. Between the values of energy $7659.2 \mathrm{~cm}^{-1}<T_{e}<8788.4 \mathrm{~cm}^{-1}$, Ramond et al. [52] suggested to these values an assignment to one of the three states ${ }^{3} \Phi_{\mathrm{i}},{ }^{3} \Delta_{\mathrm{i}}$ and ${ }^{3} \Pi_{\mathrm{i}}$. By comparing this data to our calculated values in the present work (Table 1), the assignment to the states ${ }^{3} \Phi_{\mathrm{I}}$ and ${ }^{3} \Delta_{\mathrm{I}}$ are excluded since $T_{e}\left((2)^{3} \Phi=5271.9 \mathrm{~cm}^{-1}\right), T_{e}\left((3)^{3} \Phi=13911.9 \mathrm{~cm}^{-1}\right)$, 
$T_{e}\left((1)^{3} \Delta=10185.1 \mathrm{~cm}^{-1}\right)$, and $T_{e}\left((2)^{3} \Delta=10243.65 \mathrm{~cm}^{-1}\right)$, therefore the only possible assignment is $(2)^{3} \Pi$. These values of energy obtained by Ramond et al. [52] can fit also with the energy of the state $(4)^{1} \Delta$ in Table 1 , but since this state is not suggested by the authors, this assignment is excluded in the present work. The same authors [52] obtained experimentally for the state ${ }^{1} \Pi$ the energy $T_{e}=10095.1 \mathrm{~cm}^{-1}$ which fits with our calculated value of the state $(2)^{1} \Pi$ with the relative difference $\Delta T_{e} / T_{e}=6.7 \%$.

The values of the energy $T_{e}$ of the states ${ }^{3} \Phi_{2,3,4}$ and ${ }^{1} \Delta$ obtained experimentally by Moravec and Jarrold [53] are respectively in good agreement and assignment with the $(2)^{3} \Phi$ and (4) $)^{1} \Delta$ of the present work. Our calculated value of $\omega_{e}$ for the state (4) $)^{1} \Delta$ is in good agreement with that measured by Moravec and Jarrold [53] with relative difference $\Delta \omega_{e} / \omega_{e}=5.4 \%$. The ${ }^{3} \Pi_{1,2,3}$ states detected by Moravec and Jarrold [53] are in good agreement and assignment with the $(3)^{3} \Pi$ of the present work (Table 1).

The assignment of the three states $\mathrm{a}\left({ }^{1} \Delta\right), \mathrm{b}\left({ }^{1} \Sigma^{+}\right)$and $c\left({ }^{1} \Pi\right)$ detected experimentally by $\mathrm{Wu}$ and Wang [54] are in very good agreement with our assignment of the states (4) ${ }^{1} \Delta,{ }^{1} \Sigma^{+}$and (3) ${ }^{1} \Pi$ with the relative differences $\Delta T_{e} / T_{e}$ $\left(\mathrm{a}\left({ }^{1} \Delta\right)\right)=6 \%, \Delta T_{e} / T_{e}\left(\mathrm{~b}\left({ }^{1} \Sigma^{+}\right)\right)=0.5 \%, \Delta T_{e} / T_{e}\left(\mathrm{c}\left({ }^{1} \Pi\right)\right)=$ $1.3 \%$ respectively. Baushlicher Jr. [21] calculated the nearest ${ }^{1} \Sigma^{+}$state at $8340 \mathrm{~cm}^{-1}$ above the ${ }^{3} \Sigma^{-}$which is in disagreement with our calculated value and those of $\mathrm{Wu}$ and Wang [54]. The MRCI calculated values of $T_{e}$, in the present work, for the $(2)^{3} \Phi$ and $(3)^{3} \Phi$ states are respectively 5271.9 and $13911.9 \mathrm{~cm}^{-1}$, therefore the possible assignment of the $\mathrm{B}\left({ }^{3} \Phi\right)$ state, where $T_{e}=10025.7 \mathrm{~cm}^{-1}$, investigated by $\mathrm{Wu}$ and Wang [54] is the (3) ${ }^{3} \Phi$ (Table 1). The calculated values of $r_{e}$ and $\omega_{e}$ by Bakalbassiss et al. [24] for the states ${ }^{3} \Delta$ and ${ }^{1} \Sigma^{+}$, which are fitting with our $(4)^{3} \Delta$ and ${ }^{1} \Sigma^{+}$, are in disagreement with the values calculated in the present work, while there are good agreements between our data and those of Bauschlicher Jr. and Maitre [56] for the values of $r_{e}$ for these states with the relative differences $\Delta r_{e} / r_{e}\left({ }^{3} \Delta\right)=9 \%$ and $\Delta r_{e} / r_{e}\left({ }^{1} \Sigma^{+}\right)=5 \%$.

The ${ }^{3} \Sigma^{-}$at $16,000 \mathrm{~cm}^{-1}$ predicted by Friedman-Hill and Field [18] is in very good agreement with the $(2)^{3} \Sigma^{-}$state calculated in the present work with the relative difference $\Delta T_{e} / T_{e}=0.3 \%$. The detected ${ }^{3} \Pi$ state by Walch and Goddard [20] at $\approx 6000 \mathrm{~cm}^{-1}$ fits with our assignment of the state $(2)^{3} \Pi$ where the relative difference in energy $\Delta T_{e} / T_{e}=12 \%$. The comparison of our results with the most recent investigation on the molecule $\mathrm{NiO}$ [58] shows an excellent agreement with our results for the state ${ }^{3} \Sigma^{-}$, but our assumption for the energies 19452.6 $\mathrm{cm}^{-1}$ and $19447.3 \mathrm{~cm}^{-1}$ are in agreement with that given by $\mathrm{Wu}$ and Wang [54]. Because of the breakdown of the Born-Oppenheimer approximation at the crossing and avoided crossing of the potential energy curves near the minimum of the potential energy curves there is no cal- culation of the spectroscopic constants of other calculated electronic states where the potential energy curves are given in Figures 1-4.

The electric dipole moment is an effective gauge of the ionic characters; it is helping for understanding the macroscopic properties of imperfect gases, liquids and solids and is of great utility in the construction of molecular orbital. The expectation value of this operator is sensitive primarily to the nature of the least energetic and most chemically relevant valence electrons. To understand the ionic behavior of the excited electronic states we have presented in Figures 5-8 the adiabatic permanent dipole moment for the investigated electronic states in the range of the considered internuclear distance. It was seen that the variation of the adiabatic dipole moment is very important in the vicinity of the avoided crossings and the position of the peaks corresponds to the positions of these avoided crossings of the adiabatic curves. Each time an adiabatic state loses its ionic character, it becomes neutral and the corresponding dipole moment tends towards zero. One can notice the fit between the positions of the intersections of the permanent dipole moment curves and the position of the avoided crossings of the corresponding potential energy curves for the following states $(4)^{1} \Delta /(5)^{1} \Delta(6)^{1} \Delta /(7)^{1} \Delta$ and $(1)^{3} \Delta /(3)^{3} \Delta$ at $1.631 \AA, 1.812 \AA$ and $1.811 \AA$ respectively. These fittings confirm the validity and the accuracy of the investigated data in the present work on the molecule NiO.

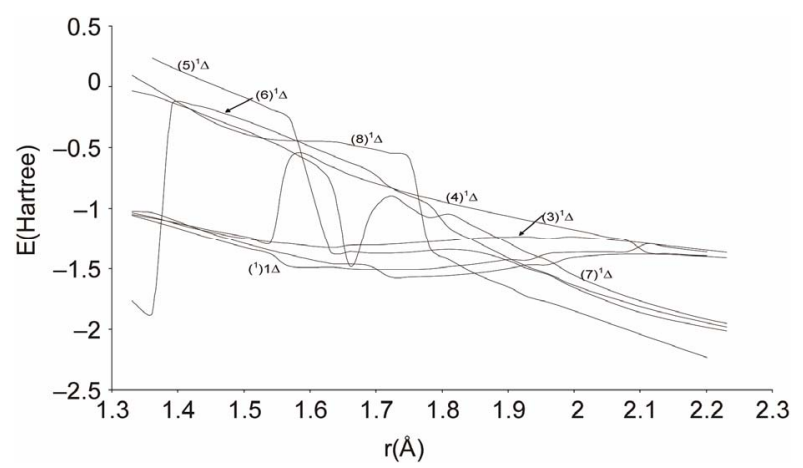

Figure 5. Permanent dipole moment curves of the lowest singlet ${ }^{1} \Delta$ and ${ }^{1} \Sigma$ states of the molecule NiO.

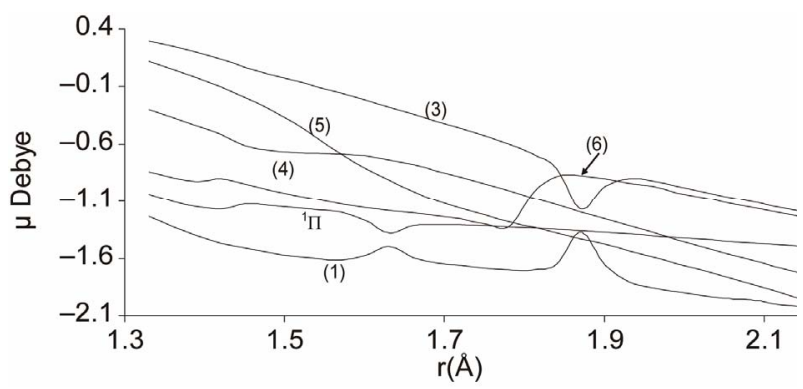

Figure 6. Permanent dipole moment curves of the lowest singlet ${ }^{1} \Pi$ states of the molecule $\mathrm{NiO}$. 


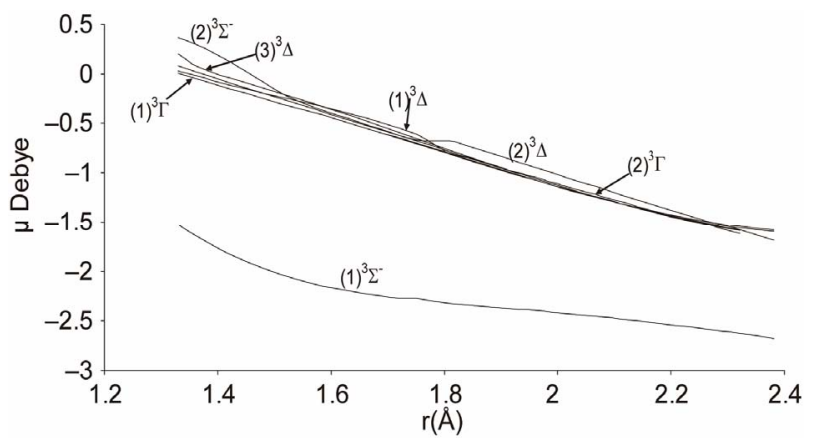

Figure 7. Permanent dipole moment curves of the lowest singlet ${ }^{3} \Sigma^{-},{ }^{3} \Delta$ and ${ }^{3} \Gamma$ states of the molecule NiO.

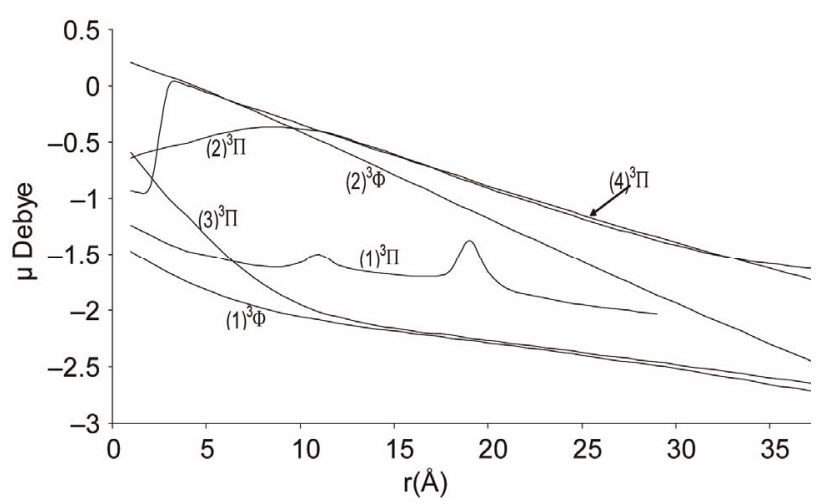

Figure 8. Permanent dipole moment curves of the lowest triplet ${ }^{3} \Pi$ and ${ }^{3} \Phi$ states of the molecule NiO.

\subsection{The Vibration-Rotation Calculation}

Within the Born-Oppenheimer approximation, the vibration rotation motion of a diatomic molecule in a given electronic state is governed by the radial Schrödinger equation

$$
\left[\frac{\mathrm{d}^{2}}{\mathrm{~d} r^{2}}+\frac{2 \mu}{\hbar^{2}}\left(E_{v J}-U(r)\right)-\frac{\lambda}{r^{2}}\right] \Psi_{v J}(r)=0
$$

where $r$ is the internuclear distance, $v$ and $J$ are respecttively the vibrational and rotational quantum numbers, $\lambda=J(J+1) \quad E_{v J}$ and $\Psi_{v J}$ are respectively the eigenvalue and the eigenfunction of this equation. In the perturbation theory these functions can be expanded as

$$
\begin{gathered}
E_{v J}=\sum_{n=0} e_{n} \lambda^{n} \\
\Psi_{v J}(r)=\sum_{n=0} \Phi_{n}(r) \lambda^{n}
\end{gathered}
$$

with $e_{0}=E_{v}, e_{1}=B_{v}, e_{2}=-D_{v}, \phi_{0}$ is the pure vibration wave function and $\phi_{\mathrm{n}}$ its rotational corrections. By replacing Equations (2) and (3) into Equation (1) and since this equation is satisfied for any value of $\lambda$, one can write [47,59-63]

$$
\phi_{0}^{\prime \prime}(r)+\left[e_{0}-U(r)\right] \phi_{0}(r)=0
$$

$$
\begin{array}{r}
\phi_{1}^{\prime \prime}(r)+\left[e_{0}-U(r)\right] \phi_{1}(r)=-\left[e_{1}-R(r)\right] \phi_{0}(r) \quad(5 \mathrm{a}) \\
\phi_{2}^{\prime \prime}(r)+\left[e_{0}-U(r)\right] \phi_{2}(r)=-\left[e_{1}-R(r)\right] \phi_{1}(r)-e_{2} \phi_{0}(r) \\
\cdots \\
\phi_{n}^{\prime \prime}(r)+\left[e_{0}-U(r)\right] \phi_{n}(r)=R(r) \phi_{n-1}-\sum_{m=1}^{n} e_{m} \phi_{n-m}(r)(5 \mathrm{n})
\end{array}
$$

where $R(r)=1 / r^{2}$, the first equation is the pure vibrational Schrödinger equation and the remaining equations are called the rotational Schrödinger equations. One may project Equations (7) onto $\phi_{0}$ and find

$$
\begin{gathered}
\left\langle\phi_{0} \mid \phi_{0}\right\rangle e_{1}=\left\langle\phi_{0}\left|\frac{1}{r^{2}}\right| \phi_{0}\right\rangle \\
\left\langle\phi_{0} \mid \phi_{0}\right\rangle e_{2}=\left\langle\phi_{0}\left|\frac{1}{r^{2}}\right| \phi_{1}\right\rangle-e_{1}\left\langle\phi_{0} \mid \phi_{1}\right\rangle \\
\cdots \\
\left\langle\phi_{0} \mid \phi_{0}\right\rangle e_{n}=\left\langle\phi_{0}\left|\frac{1}{r^{2}}\right| \phi_{n-1}\right\rangle-\sum_{m=1}^{n-1} e_{m}\left\langle\phi_{n-m} \mid \phi_{0}\right\rangle
\end{gathered}
$$

Once $e_{0}$ is calculated from Equation (4), $e_{1}, e_{2}$, $e_{3} \cdots$ can be obtained by using alternatively Equations (5) and (6). By using the canonical functions approach [47] and the cubic spline interpolation between each two consecutive points of the PECs obtained from the $a b$ initio calculation of the $\mathrm{NiO}$ molecule, the eigenvalue $E_{v}$, the rotational constant $B_{v}$, the distortion constant $D_{v}$, and the abscissas of the turning point $r_{\min }$ and $r_{\max }$ have been calculated up to the vibrational levels $v=12$ for the investigated electronic states in the present work. These values for the state $\mathrm{X}^{1} \sum^{+}$and the $(2)^{3} \Phi$ (as illustration) are given in Table 2. The comparison of the investigated values of $B_{v}$ and $D_{v}$ in literature $[18,19,25]$ with our calculated values for these states showed a good agreement with relative difference $\Delta B_{v} / B_{v} \approx 8 \%$ for $v=0,1$ and $\Delta D_{v} / D_{v}$ equal $7.5 \%$ and $2.4 \%$ respectively for $v=1$ and $v=2$.

\section{Conclusion}

In the present work, the $a b$ initio investigation for the 40 low-lying singlet and triplet electronic states of the $\mathrm{NiO}$ molecule has been performed via CAS-SCF/MRCI and CASPT2 methods. The potential energy and the dipole moment curves have been determined along with the spectroscopic constants $T_{e}, r_{e}, \omega_{e}$, and the rotational constant $B_{e}$ for the lowest-lying electronic states. The comparison of our results, for different states, with those obtained experimentally and theoretically shows a good agreement. By using the canonical functions approach [47,59-63], the eigenvalue $E_{v}$, the rotational constant $B_{v}$, 
Table 2. Rovibrational calculation of the $X^{3} \Sigma^{-}$and $(2)^{3} \Phi$ of the molecule NiO.

\begin{tabular}{|c|c|c|c|c|c|}
\hline \multicolumn{6}{|c|}{$\mathrm{X}^{3} \Sigma^{-}$} \\
\hline V & $E_{v}\left(\mathrm{~cm}^{-1}\right)$ & $B_{v} \times 10\left(\mathrm{~cm}^{-1}\right)$ & $D_{v} \times 10^{7}\left(\mathrm{~cm}^{-1}\right)$ & $R_{\min }(\AA)$ & $R_{\max }(\AA)$ \\
\hline \multirow{4}{*}{0} & \multirow{4}{*}{383.3} & $4.66^{\mathrm{a} 1}$ & $6.83^{\mathrm{a} 1}$ & \multirow{4}{*}{1.638} & \multirow{4}{*}{1.750} \\
\hline & & $5.05823(11)^{\mathrm{h}}$ & $7.387^{\mathrm{h}}$ & & \\
\hline & & $5.05836^{\mathrm{r}}$ & $7.48^{\mathrm{r}}$ & & \\
\hline & & $5.0369^{\mathrm{i}}$ & & & \\
\hline \multirow{3}{*}{1} & \multirow{3}{*}{1147.8} & 4.61 & 7.64 & \multirow{3}{*}{1.600} & \multirow{3}{*}{1.808} \\
\hline & & $5.01488(49)^{\mathrm{h}}$ & $7.46(44)^{\mathrm{h}}$ & & \\
\hline & & $5.01544^{\mathrm{r}}$ & $7.52^{\mathrm{r}}$ & & \\
\hline 2 & 1880.5 & 4.58 & 5.83 & 1.577 & 1.845 \\
\hline 3 & 2631.2 & 4.54 & 7.55 & 1.558 & 1.877 \\
\hline 4 & 3360.9 & 4.49 & 5.50 & 1.544 & 1.906 \\
\hline 5 & 4097.3 & 4.46 & 7.48 & 1.531 & 1.933 \\
\hline 6 & 4817.6 & 4.42 & 5.34 & 1.521 & 1.958 \\
\hline 7 & 5539.5 & 4.38 & 6.88 & 1.511 & 1.983 \\
\hline 8 & 6250.2 & 4.34 & 6.68 & 1.502 & 2.006 \\
\hline 9 & 6952.3 & 4.30 & 7.13 & 1.493 & 2.030 \\
\hline 10 & 7644.4 & 4.27 & 7.27 & 1.485 & 2.052 \\
\hline 11 & 8327.0 & 4.24 & 7.17 & 1.478 & 2.074 \\
\hline \multicolumn{6}{|c|}{$(2)^{3} \Phi$} \\
\hline 0 & 276.6 & 4.45 & 1.11 & 1.696 & 1.806 \\
\hline 1 & 842.8 & 4.48 & 1.05 & 1.660 & 1.854 \\
\hline 2 & 1420.9 & 4.50 & 1.40 & 1.640 & 1.890 \\
\hline 3 & 1975.3 & 4.53 & 1.33 & 1.617 & 1.919 \\
\hline 4 & 2524.8 & 4.55 & 1.63 & 1.602 & 1.946 \\
\hline
\end{tabular}

${ }^{\mathrm{a} 1}$ Present work with MRCI calculation; ${ }^{\mathrm{h}}$ Ref. $19 ;{ }^{\mathrm{r}}$ Ref. 25; ${ }^{\mathrm{i}}$ Ref. 18.

and the abscissas of the turning points $r_{\min }$ and $r_{\max }$ have been calculated up to the vibrational level $v=12$. Eleven electronic states have been investigated in the present work for the first time.

\section{REFERENCES}

[1] A. J. Merer, "Spectroscopy of the Diatomic 3d Transition Metal Oxides," Annual Review of Physical Chemistry, Vol. 40, 1989, pp. 407-438. doi:10.1146/annurev.pc.40.100189.002203

[2] R. W. Field, D. P. Baldwin, E. J. Hill, M. Li and M. C. McCarthy, "Spectroscopy Beyond Molecular Constants," Spectrochimica Acta Part A: Molecular Spectroscopy, Vol. 45, No. 1, 1989, pp. 75-89. doi:10.1016/S0584-8539(89)80090-X

[3] F. J. Morin, "Electrical Properties of NiO," Physical Review, Vol. 93, No. 6, 1954, pp. 1199-1204.

[4] D. Adler and J. Feinleib, "Electrical and Optical Properties of Narrow-Band Materials," Physical Review B, Vol. 2, No. 8, 1970, pp. 3112-3134.

[5] A. J. Bosman and H. J. Van Daal, "Small-Polaron versus
Band Conduction in Some Transition-Metal Oxides," Advances in Physics, Vol. 19, No. 77, 1970, pp. 1-117. doi:10.1080/00018737000101071

[6] P. Pushparajah and S. Radhakrishna, "Transparent Conducting Lithium-Doped Nickel Oxide Thin Films by Spray Pyrolysis Technique," Journal of Materials Science, Vol. 32, No. 11, 1997, pp. 3001-3006. doi:10.1023/A:1018657424566

[7] A. J. Bosman and Crrevecoeur, "Mechanism of the Electrical Conduction in Li-Doped NiO," Physical Review, Vol. 144, No. 2, 1965, pp. 763-770.

[8] S. Van Houten, "Semiconduction in $\mathrm{Li}_{x} \mathrm{Ni}_{1-x} \mathrm{O}$," Journal of Physics and Chemistry of Solids, Vol. 17, No. 1-2, 1960, pp. 7-17. doi:10.1016/0022-3697(60)90169-4

[9] R. R. Heikes and W. D. Johnston, "Mechanism of Conduction in Li-Substituted Transition Metal Oxides," Journal of Chemical Physics, Vol. 26, No. 3, 1957, pp. 582-588. doi:10.1063/1.1743350

[10] P. Lunkenheimer, A. Loidl, C. R. Ottermann and K. Bange, "Correlated Barrier Hopping in NiO Films," Physical Review B, Vol. 44, No. 11, 1991, pp. 5927-5930.

[11] S. A. Makhlouf, F. T. Parker, F. E. Spada and A. E. Ber- 
kowitz, "Magnetic Anomalies in NiO Nanoparticles," Journal of Applied Physics, Vol. 81, No. 8, 1997, pp. 5561-5564. doi:10.1063/1.364661

[12] J. T. Richardson, D. I. Yiagas, B. Turk, K. Forster and M. V. Twigg, "Origin of Superparamagnetism in Nickel Oxide," Journal of Applied Physics, Vol. 70, No. 11, 1991, pp. 6977-6983. doi:10.1063/1.349826

[13] F. Bødker, M. F. Hansen, C. B. Koch and S. Mørup, "Particle Interaction Effects in Antiferromagnetic NiO Nanoparticles," Journal of Magnetism and Magnetic Materials, Vol. 221, No. 1-2, 2000, pp. 32-36. doi:10.1016/S0304-8853(00)00392-9

[14] R. H. Kodama, S. A. Makhlouf and A. E. Berkowitz, "Finite Size Effects in Antiferromagnetic NiO Nanoparticles," Physical Review Letters, Vol. 79, No. 7, 1997, pp. 1393-1396.

[15] B. Rosen, "Spectra of Diatomic Oxides by the Method of Exploded Wire," Nature, Vol. 156, 1945, pp. 570-570. doi:10.1038/156570a0

[16] D. W. Green, G. T. Reedy and J. G. Kay, "Matrix-Isolated $\mathrm{FeO}, \mathrm{NiO}$, and $\mathrm{CoO}$ Ground-State Vibrational Frequencies," Journal of Molecular Spectroscopy, Vol. 78, No. 2, 1979, pp. 257-266. doi:10.1016/0022-2852(79)90005-5

[17] V. I. Srdanov and D. O. Harris, "Laser Spectroscopy of NiO: The ${ }^{3} \Sigma^{-}$ground State," Journal of Chemical Physics, Vol. 89, No. 5, 1988 , pp. 2748-2753. doi:10.1063/1.455711

[18] E. J. Friedman-Hill and R.W. Field, "Analysis of the $[16.0]^{3} \Sigma^{-}-\mathrm{X}^{3} \Sigma^{-}$and $[16.0] \Sigma^{-}-[4.3]^{3} \Pi_{i}$ Band Systems of the NiO Molecule," Journal of Molecular Spectroscopy, Vol. 155, 1992, pp. 259-276. doi:10.1016/0022-2852(92)90516-Q

[19] R. S. Ram and P. F. Bernath, "Fourier Transform Infrared Emission Spectroscopy of a New $\mathrm{A}^{3} \Pi_{i}-\mathrm{X}^{3} \Sigma^{-}$System of NiO," Journal of Molecular Spectroscopy, Vol. 155, 1992, pp. 315-325. doi:10.1016/0022-2852(92)90520-X

[20] S. P. Walch and W. A. Goddard III, "Electronic States of the Nickel Oxide Molecule," Journal of the American Chemical Society, Vol. 100, No. 5, 1978, pp. 1338-1348. doi:10.1021/ja00473a002

[21] C. W. Bauschlicher Jr., "On the Similarity of the Bonding NiS and NiO," Chemical Physics, Vol. 93, 1985, pp. 399404. doi:10.1016/0301-0104(85)87004-X

[22] C. W. Bauschlicher Jr., C. J. Nelin and P. S. Bagus, "Transition Metal Oxides: CrO, MoO, NiO, PdO, AgO," Journal of Chemical Physics, Vol. 82, No. 7, 1985, pp. 3265-3277. doi:10.1063/1.448224

[23] M. Dolg, U. Wedig, H. Stoll and H. Preuss, " $A b$ initi Pseudopotential Study of the First Row Transition Metal Monoxide and Iron Monohydride," Journal of Chemical Physics, Vol. 86, No. 4, 1987, pp. 2123-2131. doi: $10.1063 / 1.452110$

[24] E. G. Bakalbassis, M. D. Stiakaki, A. C. Tsipis and C. A. Tsipis, "Ground and Low-Lying Excited State Properties of the First-Row Transition-Metal Oxide Diatomics Calculated by an Improved ASED-MO Model," Chemical Physics, Vol. 205, No. 3, 1996, pp. 389-399. doi:10.1016/0301-0104(95)00417-3

[25] K. Namiki and S. Saito, "Microwave Spectrum of the $\mathrm{NiO}$ Radical in the $\mathrm{X}^{3} \Sigma^{-}$-State," Chemical Physics Letters, Vol. 252, No. 5-6, 1996, pp. 343-347. doi:10.1016/0009-2614(96)00195-9

[26] H. Y. H. Chan, S. Zou and M. J. Weaver, "Mechanistic Differences between Electrochemical and Gas-Phase Thermal Oxidation of Platinum-Group Transition Metals as Discerned by Surface-Enhanced Raman Spectroscopy," Journal of Physical Chemistry B, Vol. 103, No. 50, 1999, pp. 11141-11151. doi:10.1021/jp992500o

[27] T. Sasaki, N. Koshizaki and K. M. Beck, "Comparison of $\mathrm{Pt} / \mathrm{TiO}_{2}$ Nanocomposite Films Prepared by Sputtering and Pulsed Laser Deposition," Applied Physics A: Materials Science \& Processing, Vol. 69, No. 7, 1999, pp. S771S774. doi: $10.1007 / \mathrm{s} 003390051526$

[28] L. Maya, L. Riester, T. Thundat and C. S. Yust, "Characterization of Sputtered Amorphous Platinum Dioxide Films," Journal of Applied Physics, Vol. 84, No. 11, 1998, pp. 6382-6387. doi:10.1063/1.368883

[29] O. L. Shcheka, N. V. Dobrodey and T. B. Emelina, "Quantum Chemical Study of Catalysts Based on Oxides of Transition Metals," International Journal of Quantum Chemistry, Vol. 50, No. 3, 1994, pp. 181-188. doi:10.1002/qua.560500303

[30] G. Boschloo and A. Hagfeldt, "Spectroelectrochemistry of Nanostructured NiO," Journal of Physical Chemistry B, Vol. 105, No. 15, 2001, pp. 3039-3044. doi:10.1021/jp003499s

[31] S. C. Su, J. N. Carstens and A. T. Bell, "A Study of the Dynamics of Pd Oxidation and PdO Reduction by $\mathrm{H}_{2}$ and $\mathrm{CH}_{4}$," Journal of Catalysis, Vol. 176, No. 1, 1998, pp. 125-135. doi:10.1006/jcat.1998.2028

[32] V. Biju and M. Abdul Khadar, "Dielectric Properties of Nanostructured Nickel Oxide," Journal of Materials Science, Vol.38, 2003, pp. 4055-4063. doi:10.1023/A:1026131103898

[33] J. R. Mc Bride, G. W. Graham, C. R. Peters and W. H. Weber, "Growth and Characterization of Reactively Sputtered Thin-Film Platinum Oxides," Journal of Applied Physics, Vol. 69, No. 3, 1991, pp. 1596-1605. doi:10.1063/1.347255

[34] A. Citra, G. V. Chertihin and L. Andrews, "Reactions of Laser-Ablated Nickel Atoms with Dioxygen. Infrared Spectra and Density Functional Calculations of Nickel Oxides $\mathrm{NiO}, \mathrm{ONiO}, \mathrm{Ni}_{2} \mathrm{O}_{2}$, and $\mathrm{Ni}_{2} \mathrm{O}_{3}$, Superoxide $\mathrm{NiOO}$, Peroxide $\mathrm{Ni}\left(\mathrm{O}_{2}\right)$, and Higher Complexes in Solid Argon," Journal of Physical Chemistry A, Vol. 101, No. 17, 1997, pp. 3109-3118. doi:10.1021/jp970019x

[35] K. P. Huber and G. Herzberg, "Molecular Spectra and Molecular Structure. IV. Constants of Diatomic Molecules," Van Nostrand Reinhold, New York, 1979.

[36] Saleh N. Abdul Al, Mahmoud Korek and Abdul Rahman Allouche, "Theoretical Electronic Structure of the Lowest-Lying States of the YI Molecule," Chemical Physics, Vol. 308, No. 1-2, 2005, pp. 1-6. doi:10.1016/j.chemphys.2004.07.032

[37] M. Korek, Y. A. Moghrabi and A. R. Allouche, "Theo- 
retical Calculation of the Excited States of the KCs Molecule Including the Spin-Orbit Interaction," Journal of Chemical Physics, Vol. 124, No. 9, 2006, Article ID: 094309. doi:10.1063/1.2173239

[38] M. Korek, S. Bleik and A. R. Allouche, "Theoretical Calculation of the Low Laying Electronic States of the Molecule NaCs with Spin-Orbit Effect,“ Journal of Chemical Physics, Vol. 126, No. 12, 2007, Article ID: 124313. doi:10.1063/1.2710257

[39] F. Taher-Mansour, A. R. Allouche and M. Korek, "Theoretical Electronic Structure of the Lowest-Lying States of $\mathrm{ScCl}$ Molecule below 22,500 $\mathrm{cm}^{-1}$," Journal of Molecular Spectroscopy, Vol. 248, No. 1, 2008, pp. 61-65. doi:10.1016/j.jms.2007.11.012

[40] M. Korek, S. Kontar, F. Taher-Mansour and A. R. Allouche, "Theoretical Electronic Structure of the Molecule ScI," International Journal of Quantum Chemistry, Vol. 109, No. 2, 2009, pp. 236-242. doi:10.1002/qua.21779

[41] M. Korek, S. Al-Shawa and G. A. Younes, "Theoretical Calculation of the Electronic Structure of the Molecule LiRb Including the Spin-Orbit Interaction," Journal of Molecular Structure: THEOCHEM, Vol. 899, No. 1-3, 2009, pp. 25-31. doi:10.1016/j.theochem.2008.12.006

[42] M. Korek and S. N. Abdul-Al, "Rovibrational Study and Dipole Moment Calculation of the Molecule YF with Spin-Orbit Interaction," Chemical Physics, Vol. 355, No. 2-3, 2009, pp. 130-134. doi:10.1016/j.chemphys.2008.11.022

[43] A. Hamdan, M. Korek, "Theoretical Calculation of the Low-Lying Sextet Electronic States of CrF Molecule," Chemical Physics, Vol. 369, No. 1, 2010, pp. 13-18. doi:10.1016/j.chemphys.2010.01.023

[44] A. Hamdan, and M. Korek, "Theoretical Calculation of the Low-Lying Quartet States of the CrF Molecule," Canadian Journal of Chemistry, Vol. 89, No. 10, 2011, pp. 1304-13011. doi:10.1139/v11-082

[45] A. Hamdan and M. Korek, "Theoretical Study with Vibration-Rotation and Dipole Moment Calculations of Quartet States of the CrCl Molecule," International Journal of Quantum Chemistry, Vol. 111, No. 12, 2011, pp. 2960-2965. doi:10.1002/qua.22602

[46] J. R. Smith, H. Schlosser, W. Leaf, J. Ferrante and J. H. Rose, "Connection Between Energy Relations of Solids and Molecules," Physic Review A, Vol. 39, 1989, pp. 514517.

[47] M. Korek, "A One Directional Shooting Method for the Computation of Diatomic Centrifugal Distortion Constants," Computer Physics Communications, Vol. 119, No. 2-3, 1999, pp. 169-178. doi:10.1016/S0010-4655(98)00180-5

[48] W. R. Wadt, P. J. Hay, “Ab initio Effective Core Potentials for Molecular Calculations. Potentials for the Transition Metal Atoms Sc to Hg," Journal of Chemical Physics, Vol. 82, No. 1, 1985, pp. 270-284. doi:10.1063/1.448799

[49] N. Godbout, D. R. Salahub, J. Andzelm and E. Wimmer, "Optimization of Gaussian-Type Basis Sets for Local Spin Density Functional Calculations. Part I. Boron through Neon, Optimization Technique and Validation,"
Canadian Journal of Chemistry, Vol. 70, No. 2, 1992, pp. 560-571. doi:10.1139/v92-079

[50] H.-J. Werner, P. J. Knowles, R. Lindh, F. R. Manby, M. Schütz, P. Celani, T. Korona, G. Rauhut, R. D. Amos, A. Bernhardsson, A. Berning, D. L. Cooper, M. J. O. Deegan, A. J. Dobbyn, F. Eckert, C. Hampel, G. Hetzer, A. W. Lloyd, S. J. McNicholas, W. Meyer, M. E. Mura, A. Nicklaß, P. Palmieri, R. Pitzer, U. Schumann, H. Stoll, A. J. Stone, R. Tarroni and T. Thorsteinsson, "MOLPRO Is a Package of Ab initio Programs." http://www.molpro.net/info/molpro2006.1/molpro_manua 1

[51] A. R. Allouche, "Gabedit-A Graphical User Interface for Computational Chemistry Softwares," Journal of Computational Chemistry, Vol. 32, No. 1, 2011, pp. 174-182. doi:10.1002/jcc. 21600

[52] T. M. Ramond, G. E. Davico, F. Hellberg, F. Svedberg, P. Salén, P. Söderqvist and W. C. Lineberger, "Photoelectron Spectroscopy of Nickel, Palladium, and Platinum Oxide Anions," Journal of Molecular Spectroscopy, Vol. 216, No. 1, 2002, pp. 1-14. doi:10.1006/jmsp.2002.8669

[53] V. D. Moravec and C. C. Jarrold, "Study of the LowLying States of $\mathrm{NiO}^{-}$and $\mathrm{NIO}$ Using Anion Photoelectron Spectroscopy," Journal of Chemical Physics, Vol. 108, No. 5, 1998, pp. 1804-18011. doi:10.1063/1.475557

[54] H. Wu and L. S. Wang, "A Study of Nickel Monoxide (NiO), Nickel Dioxide (ONiO), and $\mathrm{Ni}\left(\mathrm{O}_{2}\right)$ Complex by Anion Photoelectron Spectroscopy," Journal of Chemical Physics, Vol. 107, No. 1, 1997, pp. 16-21. doi: $10.1063 / 1.474362$

[55] O. Gropen, U. Wahlgren and L. Pettersson, "Effective Core Potential Calculation on Small Molecules Containing Transition Metal Atoms," Chemical Physics, Vol. 66, 1982, pp. 459-464. doi:10.1016/0301-0104(82)88047-6

[56] C. W. Bauschlicher Jr. and P. Maitre, "Theoretical Study of the First Transition Row Oxides and Sulfides," Theoretica Chimica Acta, Vol. 90, No. 2-3, 1995, pp. 189203. doi:10.1007/BF01113847

[57] S. C. Chung, S. Krüger, G. Pacchioni and N. Rösch, "Relativistic Effects in the Electronic Structure of the Monoxides Andmonocarbonyls of Ni, Pd, and Pt: Local and Gradient-Corrected Density Functional Calculations," Journal of Chemical Physics, Vol. 102, 1995, pp. 36933701. doi:10.1063/1.468551

[58] R. L. Gattinger, E. J. Llewellyn and W. F. J. Evans, "Chemiluminescent NiO Emissions: Band Systems and Spectral Simulation," Canadian Journal of Physics, Vol. 89, No 8, 2011, pp. 869-874. doi:10.1139/p11-068

[59] M. Korek and H. Kobeissi, "Diatomic Centrifugal Distortion Constants for a RKR Potential: The Canonical Functions Method," Journal of Molecular Spectroscopy, Vol. 145, No. 2, 1991, pp. 448-450. doi:10.1016/0022-2852(91)90131-S

[60] A. El-Hajj, H. Kobeissi and M. Korek, "SSM: A Set of Subprograms for Calculating Eigenvalues for a Diatomic Molecule Using a Simplified Shooting Method," Computer Physics Communications, Vol. 74, No. 2, 1992, pp. 297-302. doi:10.1016/0010-4655(93)90099-X

[61] M. Korek and H. Kobeissi, "Highly Accurate Diatomic 
Centrifugal Distortion Constants for High Orders and High Levels," Journal of Computational Chemistry, Vol. 13, No. 9, 1992, pp. 1103-1108. doi:10.1002/jcc.540130909

[62] H. Kobeissi and M. Korek, "One Compact Analytic Expression of the Diatomic Centrifugal Distortion Constants to Any Order," Journal of Physics B: Atomic, Molecular and Optical Physics, Vol. 26, No. 3, 1993, pp. L35-L37. doi:10.1088/0953-4075/26/3/001

[63] M. Korek and H. Kobeissi, "Diatomic Centrifugal Distortion Constants for Large Orders at Any Level: Application to the $\mathrm{XO}_{g}^{+}-\mathrm{I}_{2}$ State," Canadian Journal of Chemistry, Vol. 71, No. 3, 1993, pp. 313-317. doi: $10.1139 / \mathrm{v} 93-046$ 